\title{
Prenatal Sitogenetik Anormallikler ve Ultrasonografik olarak Saptanan Fetal Anomalilerin Korelasyonu
}

\author{
Prenatal Cytogenetic Abnormalities and the Correlation of Ultrasonographically Detected Fetal Anomalies
}

${ }^{1}$ Emine İkbal Atlı, ${ }^{1}$ Engin Atlı, ${ }^{1}$ Sinem Yalçıntepe, ${ }^{1}$ Çisem Mail, ${ }^{1}$ Selma Demir, ${ }^{1}$ Hakan Gurkan,

(ii)
${ }^{1}$ Trakya Üniversitesi Tip Fakültesi Tibbi Genetik Ana Bilim Dalı, Edirne, Türkiye

${ }^{2}$ Trakya Üniversitesi Tip Fakültesi Kadın Hastalıkları ve Doğum Anabilim Dalı
Correspondence: Emine İkbal ATLI

Trakya Üniversitesi Tip Fakültesi Trbbi Genetik Ana Bilim Dalı, Edirne, Türkiye

e-mail: emine.ikbal@gmail.com

\section{Özet}

Bu çalışmada, Trakya Üniversitesi Tip Fakültesi Hastanesi'nde 8 yıllık süreçte anormal ultrasonografi bulguları ile gelen 141 adet amniyosentez, 9 koryon villus ve 5 fetal kan örneği sitogenetik olarak analiz edilmiştir. Amacımız ultrasonografi taramasında anomali riski öngörülen gebeliklerdeki karyotipik anormalliklerin korelasyonunu belirlemekti. Amniyosentez, koryon villus ve kordosentez örnekleri ile yapılan hücre kültürlerinden elde edilen karyotipler değerlendirilmiştir. Ayrıca hızlı tanı için interfaz nukleuslarında X,Y,13, 18,21 kromozomları için floresan insitu hibridizasyon yöntemi ile anöploidi taraması yapılmıştır. Anormal ultrasonagrafi bulgusu ile refere edilen 155 hastadan 23 tanesinde (\%14.83) kromozom anomalisi saptanmıştır. NT artışı en sık tespit edilen ultasonografi bulgusuydu. Kromozom anomalilerinden 2 tanesi yapısal kromozom anomalisi olarak değerlendirildi. Geriye kalan 21 hastada saptanan anomaliler sayısal kromozom anomalisiydi. Bu 21 sayısal anomaliden 5 tanesi trizomi 13, 3 tanesi trizomi 18, 13 tanesi trizomi 21'dir. Trizomi 21 vakalarından 1 tanesi kordosentez materyalinden, 1 tanesi ise CVS materyalin den elde edilmiştir. Sonuçlarımız, yüksek riskli bir populasyonda kromozom anomalileriyle, ultrasonografik bulgular arasındaki ilişkinin anlamlı olduğunu ortaya çıkarırken, seçilen ultrasonografik belirteçlerin fetüsteki anöploidiyi saptamadaki geçerliliğini doğrulamaktadır.

Anahtar Kelimeler: Sitogenetik, Prenatal Tanı, Ultrasonografi

\section{Abstract}

In this study, 141 amniocentesis, 9 chorionic villus and 5 fetal blood samples, which come with abnormal ultrasonography findings representing 8 years of experience in Trakya University Medical Faculty Hospital, were analyzed cytogenetically. Our aim is to determine the correlation of karyotypic abnormalities detected by ultrasonography for the detection of fetal anomalies in prenatal diagnosis.Karyotypes in metaphases obtained from amniocentesis, chorionic villus and cordocentesis samples were evaluated. For rapid diagnosis, fluorescent in situ hybridization was performed in the interphase nuclei specific to X, Y, 13,18, 21 chromosomes. Chromosome anomalies were found in $23(14.83 \%)$ out of 155 patients referred with abnormal ultrasound findings. NT increase is the most common abnormal fetal ultrasonography finding. Two of the chromosomal anomalies were evaluated as structural chromosome analysis. Anomalies detected in the remaining 21 patients were numerical chromosome anomalies. Of these 21 numerical anomalies, 5 are trisomy 13, 3 are trisomy 18, 13 are trisomy 21. One of the 21 trisomy cases was obtained from cordocentesis material and 1 was obtained from CVS material. Our results present that the relationship between fetal chromosomal anomalies and ultrasonographic findings is significant in a high-risk population, while verifying the validity of selected ultrasonographic markers in detecting aneuploidy in the fetus.

Keywords: Genetic Diagnosis, Prenatal Diagnosis, Ultrasonography 


\section{Giriş}

Prenatal tanı, doğum öncesi bakımın temel bir parçasıdır, çünkü fetüste hafif ila şiddetli anormalliklerin tanımlanmasını sağlar. $\mathrm{Bu}$, sayede mevcut ve gelecekteki gebeliğin uygun şekilde planlanmasına ve yönetilmesine izin verir.

Anöploidi, prenatal tanı ile saptanan en yaygin genetik anormalliktir. Fetal kromozom anomalileri, birinci ve ikinci trimesterde, canlı doğan bebeklerden daha yaygındır, çünkü bu fetüsler hamilelik boyunca yüksek oranda spontan kayba uğrar. Buna ek olarak etkilenen gebeliklerin sona erdirilmesi de burada rol oynar. Fetal anöploidinin antepartum tespiti prenatal tarama programlarının ana hedeflerinden biridir. Sonografik inceleme yararlıdır çünkü anormal karyotipleri olan fetüslerde genellikle anatomik değişiklikler veya anomaliler vardır $(1,2)$.

Ultrason, fetal anormallikleri tespit etmek için hamilelik boyunca kullanılabilir. İlk trimester ultrasonografik taraması nukal saydamlık ve diğer tarama testleri ile birlikte giderek daha fazla kullanılmaktadır. Birinci trimesterdeki ultrasonagrafinin, trizomi 21 gibi anöploidi durumlarının taranmasında etkili olduğu gösterilmiştir. İlk trimesterdeki $3 \mathrm{~mm}$ veya daha büyük bir orandaki nukal kalınlık ölçümünün yüksek bir duyarlılığa sahip olduğu ve kromozom anomalileri için risk altındaki hamileliklerin belirlenmesinde özgüllük taşıdığı bildirilmiştir $(3,4)$.

Ek olarak, erken anatomik araştırmaların deneyimli bir sonografi uzmanı tarafindan yürütüldüğ̈̈nde, fenotipik yapının iyi tespit edildiği gösterilmiştir. Picklesimer ve ark. anöploidi taşıyıcısı fetusların retrospektif bir kohort çalışmasında, ultrasonagrafinin anındaki gebelik yaşının anöploidinin ultrasonagrafik belirteçlerinin saptanması üzerindeki etkisini araştırmıştır. $\mathrm{Bu}$ çalışmadaki fetal ultrasonagrafiler 14 ila 32 haftalı gebelikler arasında gerçekleştirilmiştir ve araştırmacılar anöploidinin sonografik belirteçlerinin tüm gebelik yaşlarında mevcut olduğunu göstermiştir. Daha erken gebelik yaşlarında, soft marker ve yapisal olmayan anormalliklerin saptanması daha sonraki gebelik yaşlarında ise majör anormalliklerin saptanmasına doğru bir kayma göstermiştir (5-7). Soft marker'lar belirsiz önemi olan ultrasonografi bulgularıdır. Genellikle normal fetuslarla (yani normal varyantlarla) ilişkilidir, klinik sekelleri yoktur ve geçicidir. İlerleyen gebelikle veya doğumdan sonra bu bulgularda gerileme görülür. Bununla birlikte, fetal anöploidi için artmış bir risk taşırlar ve hastanın biyokimyasal risk durumu ile birlikte değerlendirilmelidir. Bu marker'lar;

Artmış nukal kalınlık,

Nazal kemik yokluğu,

Ekojenik bağırsak,

Pyelektazi,

Uzun olması gereken kemiklerde kısalık (humerus, femur),

Ekojenik intrakardiyak odak,

Koroid pleksus kistleridir.

Tüm gebe kadınların ikinci trimesterde fetal anatomik bir araştırmaya tabi tutulması tavsiye edilir. Fetal anatomi yaklaşık 18 hafta sonra ultrasonografi yoluyla sistematik olarak değerlendirilir. Standart fetal anatomik değerlendirmelerin özellikleri Amerikan Ultrason Enstitüsü Tip uygulama kılavuzlarında ayrıntılı olarak açıklanmıştır.

İlk trimester ultrasonografisi büyük ölçüde kromozomal hastalık riskini belirlemede ense kalınlık ölçümüne odaklanır; ancak, ikinci trimester ultrasonu farkl1 genetik sendromlar için ayrı bir paterni takip eden spesifik kusurları tanımlayabilir $(7,8)$.

Üçüncü trimester ultrasonografisi, tanımlanan fetal anormalliklerin evrimini takip etmek için ikinci trimester taramasina ek olarak da kullanılabilir. Bununla birlikte, fetal genetik hastalıklar için bir tarama aracı olarak üçüncü trimester ultrasonografisi sinırlı faydaya sahiptir. 2008 yılında, Cochrane ve ark.'nın çalışmasında, seçili olmayan bir populasyonunda üçüncü trimester ultrasonografi taramasının rutin kullanımının fayda sağlamadığı sonucuna varılmıştır (9). 
Doğru bir doğum öncesi tanının anahtarı, fetüsün dikkatli bir şekilde taranması ve sonografi uzmanı tarafindan anormalliklerin belirlenmesidir. Kromozom anomalili bir fetüsün klasik sonografik bulguları artmış ense kalınlığı, yaygın fetal ödem, septasyonlu kistik higroma, böbrek ve kalp anomalileri vb. içerir. $\mathrm{Bu}$ ultrasonografi bulguları fetüste anomali teşhisine güvenilir ve özgül mü, bu doğrultuda Trakya Üniversitesi Tıp Fakültesi T1bbi Genetik ABD 'da retrospektif bir çalışma yapılmıştır. Karyotipleme altın standart olsa da, sonografinin fetüste anomali tanısının neresinde olduğunun belirlemesi amaçlanmıştır.

Klasik yöntemlerle uygulanmakta olan fetal karyotip elde etme süresi 10-17 gün arasında sürmektedir. $\mathrm{Bu}$ bekleme süresi içinde aile, önce amniyosentez işlemi sırasında bir stres yaşamakta buna ek olarak bekleme süreci boyunca stresi artmaktadır. $\mathrm{Bu}$ durum karyotiplemenin yanı sira, anöploidi taraması için rutin olarak uygulanmakta olan Floresan İn-Situ Hibridizasyon Yöntemi (FISH) ile kültür yapılmamış amniyon hücreleri kullanılarak aşılmıştır. FISH ile klasik sitogenetik yöntemde görülen kromozomların yerine, genetik materyal olarak hücre içinde bulunan yoğunlaşmamış kromatin yapısı kullanılmaktadır. FISH ile anöploidi taraması sirasında $13,18,21, \mathrm{X}$ ve $\mathrm{Y}$ kromozomlarına ait anöploidiler sık rastlanıldığı için bu kromozomları yansıtan problar kullanılır. Genelde bu kromozomların dişında olan anöploidiler, gebeliğin erken haftalarında kaybedilmektedir. FISH'in prenatal tanıda sadece sayısal anomalileri göstermesi, yöntemin bir kısıtlılığı olarak bilinmektedir. $\mathrm{Bu}$ nedenle diğer kromozom anomalilerini elimine etmek için bu olgularda klasik karyotipleme de yapılmaktadır. Ayrıca FISH çalışmalarında maternal kontaminasyon üzerinde durulması gereken bir durumdur. Yöntem, kendi içindeki sınırlılıklarına rağmen güvenilirliği kanıtlanmış bir ön tarama ve tanı yöntemidir. FISH ile sonuca ulaşma süresi 24 saat sürmekte ve çabuk verilen ön-sonuç aileyi oldukça rahatlatmaktadır.

\section{Gereç ve Yöntem}

Temmuz 2012 ile Mayıs 2020 arasında doğum öncesi tan1 merkezimizde değerlendirilen gebelerden prenatal ön tanisinda anormal USG bulguları olan, 18 yaşında veya daha büyük, 14 ila 24 haftalık gebelikler arasında 155 hasta bu çalışmaya dâhil edildi. USG muayenelerinin belgelenmiş bilgileri baş (beyin ve yüz) boyun, göğüs boşluğu kalbi, karın boşluğu, ekstremiteler (eller ve ayaklar) mesane, omurga ve genital bölgeyi içeriyordu. Tüm hastalara ve eşlerine girişimsel işlem uygulanmadan önce uygulama tekniği ve fetal kayıp oranları başta olmak üzere, işlemin riskleri ve komplikasyonları hakkında detaylı bilgi verilerek bilgilendirilmiş onam alınmıştır.

$\mathrm{Bu}$ çalışmada, Trakya Üniversitesi Tıp Fakültesi Hastanesi'nde 8 ylllı tecrübeyi temsil eden anormal USG bulguları ile gelen 141 adet amniyosentez (AC), 9 koryon villus (CVS) ve 5 fetal kan örneği sitogenetik olarak analiz edilmiştir. Amniyosentez için 16.-20. gebelik haftalarında gebelik haftası başına 1 cc amniyon sıvısı örneği alınmıştır. Tek seferde amniyosentez işlemi gerçekleştirilemeyen hastalara maksimum iki kez girişim denenmiştir ve tüm hastalarda başarılı olunmuştur. Uygulama esnasında uygun siv1 cebinde fetal k1sim ve kordon bulunmamasına dikkat edilmiştir, transplasental geçişin zaruri olduğu durumlarda plasenta yüzeyine dik olarak geçilmiştir. Amniyon sıvısı 20 ml'lik enjektörle negatif basınç uygulanarak aspire edilmiştir.

Koryon villus örneklemesi işlemi 11.-14. gebelik haftaları arasında yapılmıştır. Transabdominal yolla, 20 ml'lik enjektör yardımıyla, $10 \mathrm{mg}$ kadar fetal doku negatif basınç yardımıyla alınarak transport medyumuna aktarılmıştır. Transservikal yolla hiç koryon villus örneklemesi yapılmamıştır. Koryon villus örneklemesi yapılan hastaların tümünde tek seferde işlem başarılı olmuş ve hepsinden yeterli fetal doku elde edilmiştir.

Kordosentez girişimleri gebeliğin 15-38 haftalarında, aynı hekimler tarafindan, serbest el tekniğiyle yapıldı. Girişim yeri olarak plasental insersiyon veya kordonun serbest parçası hedeflendi. Kordosentez, plasentanın yerleşimine bağlı olarak, uygun olgularda transplasental geçilerek kord insersiyon yerinden, plasentanın posterior yerleşimli 
olduğu olgularda ise transamniotik geçilerek serbest kordondan veya kordonun plasentaya giriş noktasının 1-2 cm uzağından umbilikal venden heparinli enjektör içerisinde 1-5 cc kadar kan örneği alınarak yapıldı.

Amniyositler ve koryon villus örnekleri, $3 \mathrm{ml}$ AmnioGrow (Cytogen GmbH, Bienenweg, Almanya) ve Chang Medium-D (Irvine Scientific, Santa Ana, CA, ABD) içeren iki veya üç farklı flaskta kültüre edildi. Fetal kan örneklerinden kısa süreli hücre kültürü (72 saat) yapıldı. Fetal kan örnekleri için maternal kontaminasyon olasılı̆g 1 Apt testi ile ekarte edildi. CVS örnekleri için maternal kontaminasyon olasılığ 1 STR analizi ile ekarte edildi. Kültür sonrasında harvest işlemleri tamamlanan örneklerden preparasyon sonrasinda Leishmann-Pankreatin (GPL) ve C bantlama teknikleri ile boyanarak elde edilen metafazlar analize alındı. Her örnek için en az 25 metafaz alanı sayısal ve yapısal kromozom anomalileri açısından incelenerek, sonuçlar ISCN nomenklatürüne uygun raporlandı.

FISH çalışması: Sitogenetik amaçlı yapılan amniyosentez için 0.5-4 ml kordosentez için $0.5-1 \mathrm{ml}$ CVS materyalinden $\approx 2 \mathrm{mg}$ direk FISH çalışması için ayrılmıştır. Fikse edilerek lam üzerinde FISH çalışması için hibridizasyona uygun hale getirilen hücreler için AneuVysion EC DNA prob kiti (Vysis 30-161-075) kullanılmıştır. Cytovision Image Analyser sistemi ile uygun filtreler kullanılarak X, Y, 18 için minimum 50 nükleus, 13, 21 nolu kromozomlar için minimum 50 nükleus analiz edilmiş ve görüntüleri dijital ortama aktarılmıştır. Mozaik bulunan olgularda analiz edilen nukleus sayısı 200'e çıkarılmıştır. Tüm analizler iki ayrı kişi tarafından eş zamanlı ve kontrollü olarak tamamlanmıştır. Olgularda yapılan klasik sitogenetik analiz, FISH analizini yapan gruptan bağımsız ve körleme tekniği kullanılarak gerçekleştirilmiştir.

\section{Bulgular}

Temmuz 2012 ile Mayis 2020 arasinda yapılan bir veri tabanı araştırmasında, perinatoloji kliniğinden anormal USG bulgusu ile yönlendirilmiş 155 prenatal tanı vakası dâhil edildi. Gebe kadınların yaşı 19 ila 40 yaşları arasında ve gebelik yaşı (GA) 9 ila 32 hafta arasında değişmekteydi. Olguların ortalama gebelik sayıs $2.57 \pm 1.24$ ortalama doğum sayı1 $1.05 \pm 1.23$ ortalama abortus sayıs1 $0.23 \pm 1.12$ ortalama yaşayan çocuk say1s1 $1 \pm 0.51$ idi. Daha önce amniyosentez, koryonik villus veya kordosentez örneklemesi yapılmış, majör konjenital malformasyonlu bir fetusu olan veya pozitif maternal serum tarama testi gibi başka bir risk faktörü olan kadınlar çalışma dışı bırakıldı. İkiz gebeliği olan kadınlar da homojen bir populasyonu korumak için dışlandı. Daha önce kromozomal anormalliği olan bir çocuğu olan kadınlar da USG bulgularına bakılmaksızın invaziv prenatal tanı önerildiği için çalışma dış1 bırakıldı. USG de anomali belirteci bulunan tüm kadınlar anöploidili fetüs taşıyor olma olasılığ 1 hakkında bilgilendirilmiştir (Tablo 1).

Tablo 1. Ultrasonda saptanan anomaliye bağlı olarak anöploidi riski

\begin{tabular}{|c|c|c|}
\hline Marker & Anöploidi riski & Referanslar \\
\hline Artmış nukal kalınlık & $\begin{array}{l}\text { Oranı } 18.6 \text { kez (ortalama } \% 2.5 \text {; yaşla birlikte } \\
\text { değişir) }\end{array}$ & $10-12$ \\
\hline Nazal kemik hipoplazisi & $\begin{array}{l}\text { Burun kemiği uzunluğunda her } 1 \mathrm{~mm} \text { 'lik } \\
\text { azalma ile } 2.4 \text { kat arttı }\end{array}$ & $10,11,13$ \\
\hline $\begin{array}{l}\text { Hafif ventrikülomegali (atriyal kalınlık 10-14 } \\
\text { mm) }\end{array}$ & $\% 4$ & $10,11,14$ \\
\hline Ekojenik bağırsak & $\% 1.4$ & $10,11,15$ \\
\hline Kalpteki ekojenik odak/odaklar & $\% 1$ & $10,11,16-18$ \\
\hline İzole koroid pleksus kisti & $\begin{array}{l}\% 0.36 \text { (anne }<35 \text { yaş }) \\
\% 2.4 \text { (anne }>35 \text { yaş) }\end{array}$ & $10,11,19$ \\
\hline Tek umblikal arter & İole ise $<\% 1$ & 10,11 \\
\hline Kisa humerus/femur & $\% 0.3$ & $10,11,20$ \\
\hline $\begin{array}{l}\text { İzole renal piyelektazi }(33 \text { haftadan önce } \geq 4 \\
\mathrm{mm} / 33 \text { hafta sonra } \geq 7 \mathrm{~mm} \text { ) }\end{array}$ & $\begin{array}{l}\% 0.33 \text { (anne }<36 \text { yaş) } \\
\% 2.22 \text { (anne }>36 \text { yaş) }\end{array}$ & 10,21 \\
\hline
\end{tabular}


Anormal ultrasonografi bulgusu ile refere edilen 155 hastadan 23 tanesinde (\%14.83) kromozom anomalisi saptanmıştır. NT artış1 en sik tespit edilen anormal fetal ultrasonografi bulgusuydu (Tablo 2). Kromozom anomalilerinden 2 tanesi yapisal kromozom anomalisi olarak değerlendirildi. Geriye kalan 21 hastada saptanan anomaliler sayısal kromozom anomalisiydi. Bu 21 sayısal anomaliden 5 tanesi trizomi 13, 3 tanesi trizomi 18, 13 tanesi trizomi 21'dir. Trizomi
21 vakalarından 1 tanesi kordosentez materyalinden, 1 tanesi ise CVS materyalinden elde edilmiştir. Yapısal kromozom anomalilerinden 1 tanesi CVS materyalinden elde edilen metafazlarda saptanmıştır. Fetüste 46,--,inv(2)(p15q11.2) karyotipi elde edilmiştir. Diğer yapısal anomali amniyosentez materyalinden 46,-,dup(1)(q21;q31) olarak saptanmıştır (Tablo $3)$.

Tablo 2. Prenatal tanı olgularında saptanan ultrasonografik anomalilerin dağılımı

\begin{tabular}{llll}
\hline USG anomali bulgusu & Olgu sayısı & USG anomali bulgusu & Olgu sayısı \\
\hline Hidrosefali & 3 & Ekstremite anomalisi & 8 \\
\hline Ventrikülomegali & 10 & Diafragma hernisi & 7 \\
\hline NT artışı & 48 & Osteokondroplazi & 1 \\
Koroid pleksus kisti & 20 & Araknoid kist & 1 \\
\hline Hipoplastik sol kalp & 1 & Multiple konjenital anomali & 15 \\
Kalpte ekojen odak & 10 & Omfalosel & 1 \\
Kistik higroma & 22 & Hidrops fetalis & 1 \\
Korpus Kallosum agenezisi & 3 & ARSA & 1 \\
Orofasial defekt & 1 & Kraniyal ventrikülomegali & 1 \\
Toplam= $\mathbf{1 5 5}$ olgu & & & \\
\hline
\end{tabular}

Tablo 3. Hastalarda saptanan kromozomal anomalilerin USG bulguları ile ilişkisi.

\begin{tabular}{|c|c|c|}
\hline $\begin{array}{l}\text { Anomali çıkan hasta } \\
\text { sayısı }\end{array}$ & Kromozom anomalisi & USG anomalileri \\
\hline $13(\% 8.38)$ & $47,--,+21$ & $\begin{array}{l}\text { NT kalınlığı, multipl anomali, ARSA, nazal hipoplazi, kalpte } \\
\text { ekojen odak, koroid pleksus kisti, kistik higroma }\end{array}$ \\
\hline $5(\% 3.22)$ & $47,--,+13$ & $\begin{array}{l}\text { Kalpte ekojen odak, NT artış1, diafragma hernisi, } \\
\text { ventrikülomegali }\end{array}$ \\
\hline $3(\% 1.93)$ & $47,--,+18$ & Hidrops fetalis, kistik higroma, VSD, omfalosel \\
\hline $1(\% 0.64)$ & $46,--, \operatorname{inv}(2)(p 15 q 11.2)$ & Ventrikülomegali, kistik higroma \\
\hline $1(\% 0.64)$ & $46,--\operatorname{dup}(1)(\mathrm{q} 21 ; \mathrm{q} 31)$ & Ekstremite anomalisi, NT artışı \\
\hline Toplam: $23(\% 14.83)$ & & \\
\hline
\end{tabular}

\section{Tartışma}

Çoğu gelişmiş ülkede fetal yapısal anormalliklerin tespiti için ultrasonografi doğum öncesi taramanın ayrılmaz bir parçası haline gelmiştir. Halk sağlı̆̆ açısından, fetal anormallikler için ultrasonografi taramasının potansiyel faydaları ve sinırlamaları kapsamlı bir şekilde tartışılmıştır. Bugüne kadar, seçilmemiş populasyonlar arasında hem ölümcül hem de ölümcül olmayan anormalliklerin saptanması için ultrasonografi taramasının faydaları hakkındaki raporlar sonuçsuz kalmaktadır. Randomize kontrollü çalışmalar yapılmış ancak sonuç değişkenleri olarak perinatal mortalite ve morbidite kullanılmıştır. Dahası, araştırma ortamlarında, sonografi uzmanlarının uzmanlık seviyelerinde büyük farklılıklar vardır. Araştırma bulgularının yorumlanması, yapılan çalışmaların zaman dilimi tarafından engel oluşturmuş ve günümüzde ultrasonografi mekaniği geçmişe göre daha ileridir. $\mathrm{Bu}$ metodolojik problemler; konjenital anormalliklerin tespitinde bildirilen genel duyarlılı̆̆ın, \%14 ila 96 arasında değişen muazzam bir varyasyon olarak yansıma gösterir. $\mathrm{Bu}$ metodolojik kusurların yanı sıra, perinatal mortalitenin kullanımı ve morbidite en önemli sonuç değişkenleri olarak sorgulanabilir $(22,23)$.

$\begin{array}{lcc}\text { Ultrasonografi } & \text { taramas1, } & \text { kromozom } \\ \text { anormallikleri } & \text { olan fetüslerde } & \text { morfolojik }\end{array}$ 
anormalliklerin saptanması için iyi bir araçtır. Anöploidilerde yapısal kusurları ve yapısal olmayan bulguları (sonografik belirteçler) belirleyebiliriz. Fetal anöploidinin sonografik belirteçleri (SMFA'lar) genellikle önemsizdir, çünkü spesifite göstermezler ve sıklıkla geçicidirler. Sonografinin bu anormallikleri tespit etme duyarlılı̆g 1 bir dizi faktöre göre değişir: kromozomal anormallik tipi, gebelik yaş1, sonografi kalitesi ve sonografi uzmanının deneyimi. İlk üç aylık dönemde anöploidili fetüs taşıyan gebeliklerde sadece SMFA tanımlanabilir. İkinci üç aylık dönemde, trizomi 21'li fetüslerin \% 20'sinde, trizomi 13 ve $18^{\prime}$ li fetüslerin çoğunda majör/yapısal anormallikler gözlenmiştir. SMFA ve yapısal kusurları birleştirerek sonografi; trizomi 21 'li fetusların \%50'sini, trizomi $18^{\prime}$ 'li fetüslerin \% 80'ini ve trizomi 13'lü fetüslerin \%90'ını tanımlamayı sağlar $(24,25)$. Şener ve ark.'nın yaptıkları çalışmada 98 anormal fetal ultrasonografi bulgusu olan olguların 6'sında $(\% 6,1)$ kromozomal anomali tespit edilmiştir. Araştırmacılar, klasik trizomi 13, 18, 21 kromozom kuruluşu saptanmışlar haricinde USG anomalisi olan diğer gebelikler arasında; kısa femur nedeni ile kordosentez yapilan bir olguda 47,XX, $\mathrm{t}(8 ; 14)(\mathrm{p} 22 ; \mathrm{q} 21),+\operatorname{der}(14)(8 ; 14) \quad$ karyotipi saptanmıştır. Fetal USG de tek umblikal arter nedeni ile kordosentez yapilan bir olguda 46,XX, del(3)(p25pter) karyotipi saptanmıştır (26).

M. Erdemoğlu ve ark.'nın yaptıkları çalışmada Fetal patolojisi olan grupta kromozom anomalisi oran1 \%9,8 olarak saptandi. Tüm anomalilerin $8(\% 62)$ tanesi trizomi 21, 18, 13 idi Geriye kalan bir olgu 46,XY (9p inversiyonu), bir olgu 47,XX, +22 (22. kromozom fazla), bir olgu 46,XX, 22p+ ve bir olgu da 46,XY,+14,rob(14;21) idi (27).

Diğer bir çalışmada Dağlar ve ark 268 olguyla yaptıkları çalışmada sadece 2 anormal USG

\section{KAYNAKLAR}

1. Hook EB, Topol BB, Cross PK. The natural history of cytogenetically abnormal fetuses detected at midtrimester amniocentesis which are not terminated electively: new data and estimates of the excess and relative risk of late fetal death associated with $47,+21$ and some bulgusu olan hasta bulunmaktadır. Bunun sebebi periferdeki il ve ilçelerdeki hastanelerde bulunan ultrason cihazlarının ölçümler için yetersiz olması olabilir. Değerlendirilen bu 2 hastadan 1 tanesinde 45,X kromozom kuruluşu saptanmıştır (28).

Yüce ve ark.'nın yaptığı çalışmada 356 olgunun retrospektif analizinde anormal USG bulgusu endikasyonu olan 25 olgunun sadece birinde kromozom anomalisi (trizomi 21) saptand1. Bu olgunun 16.haftada yapilan USG değerlendirmesinde polihidoamnios, fetal batında asit ve femur uzunluğunda kısalık mevcuttur (29).

\section{Sonuç}

Sonuçlarımız, yüksek riskli bir populasyonda fetal kromozomal anomalilerle ultrasonografik bulgular arasındaki ilişkinin anlamlı olduğunu sunarken, seçilen ultrasonografik belirteçlerin fetüsteki anöploidi saptamadaki geçerliliğini doğrulamaktadır.

Sonuç olarak, ultrasonografik bulgular ile ilişkili kromozomal anormalliklerin saptanması, hem invaziv girişim gerekliliği açısından hem de uygun genetik danışmanlıkta perinatolog ve genetikçiler için çok önemlidir.

\section{Etik Kurul Onayı}

Çalışma protokolü Trakya Üniversitesi Tıp Fakültesi Bilimsel Araştırmalar Etik Kurulu, Edirne tarafindan onaylandı.

\section{Hasta Onayı}

Tüm katılımcılar çalışmaya katılmayı kabul etti ve her katılımcinın yasal vasisinden yazılı bilgilendirilmiş onam alındı.

other abnormal karyotypes. Am J Hum Genet. 1989;45:855-61.

2. Morris JK, Wald NJ, Watt HC. Fetal loss in Down syndrome pregnancies. Prenat Diagn. 1999;19:142-5.

3. Krakow D, Williams J 3rd, Poehl M, Rimoin DL, Platt LD. Use of three-dimensional 
ultrasound imaging in the diagnosis of prenatal-onset skeletal dysplasias. Ultrasound Obstet Gynecol. 2003;21:467-72.

4. Malone FD, Canick JA, Ball RH, et al. Firsttrimester or second-trimester screening, or both, for Down's syndrome. $N$ Engl J Med. 2005;353:2001-11.

5. Szabó J, Gellén J, Szemere G. First-trimester ultrasound screening for fetal aneuploidies in women over 35 and under 35 years of age. Ultrasound Obstet Gynecol. 1995;5:161-3.

6. Timor-Tritsch IE, Bashiri A, Monteagudo A, et al. Qualified and trained sonographers in the US can perform early fetal anatomy scans between 11 and 14 weeks. Am J Obstet Gynecol. 2004;191:1247-52.

7. Picklesimer AH, Moise KJ Jr, Wolfe HM. The impact of gestational age on the sonographic detection of aneuploidy. Am J Obstet Gynecol. 2005;193(3 Pt 2):1243-7.

8. American Institute of Ultrasound in Medicine. AIUM practice guideline for the performance of obstetric ultrasound examinations. $J$ Ultrasound Med. 2013;32:1083-101

9. Bricker L, Medley N, Pratt JJ. Routine ultrasound in late pregnancy (after 24 weeks' gestation). Cochrane Database Syst Rev. 2015;2015:CD001451

10. Smith-Bindman R, Hosmer W, Feldstein VA, et al. Second-trimester ultrasound to detect fetuses with Down syndrome: a meta-analysis. JAMA. 2001;285:1044-55.

11. Benacerraf BR, Neuberg D, Bromley B, et al. Sonographic scoring index for prenatal detection of chromosomal abnormalities. $J$ Ultrasound Med. 1992;11:449-58.

12. Drugan A, Johnson MP, Evans MI. Ultrasound screening for fetal chromosome anomalies. $\mathrm{Am}$ J Med Genet. 2000;90:98-107.

13. Tran LT, Carr DB, Mitsumori LM, et al. Second-Trimester Biparietal Diameter/Nasal Bone Length Ratio Is an Independent Predictor of Trisomy 21. Journal of Ultrasound in Medicine. 2005;24:805-10.

14. Kelly EN, Allen VM, Seaward G, et al. Mild ventriculomegaly in the fetus, natural history, associated findings and outcome of isolated mild ventriculomegaly: a literature review. Prenat Diagn. 2001;21:697-700.

15. Chudleigh T. Mild pylectasis. Prenat Diagn. 2001;21:936-41.

16. Sotiriadis A, Makrydimas G, Ioannidis JP. Diagnostic performance of intracardiac echogenic foci for Down syndrome: a metaanalysis. Obstet Gynecol. 2003;101(5Pt1):1009-16.

17. Penna L, Bower S. Hyperechogenic bowel in the second trimester fetus: a review. Prenat Diagn. 2000;20:909-13.

18. Walkinshaw SA. Fetal choroid plexus cysts: are we there yet? Prenat Diagn. 2000;20:65762.

19. Simon-Bouy B, Satre V, Ferec C, et al. The French Collaborative Group et al.
Hyperechogenic fetal bowel: a large French Collaborative study of 682 cases. Am J Med Genet. 2003;121A:209-13.

20. Nyberg DA, Souter VL, EL-Bastawissi A, et al. Isolated sonographic marker for detection of fetal Down syndrome in the second trimester of pregnancy. J Ultrasound Med. 2001;20:1053-63.

21. Biagiotti R, Periti E, Cariati E. Humerus and femur length in fetuses with Down syndrome. Prenat Diagn. 1994;14:429-34.

22. Romano PS, Waitzman NJ. Can decision analysis help us decide whether ultrasound screening for fetal anomalies is worth it? Ann N Y Acad Sci. 1998;847:154-72.

23. Health Council of the Netherlands. Prenatal Screening: Down's syndrome, neural tube defects, routine-ultrasonography, The Hague: Health Council of the Netherlands, publication no. $2001 / 11$.

24. Hill LM. The sonographic detection of trisomies 13, 18, and 21. Clin Obstet Gynecol. 1996;39:831-50.

25. Nyberg DA, Souter VL. Sonographic markers of fetal trisomies: second trimester. $J$ Ultrasound Med. 2001;20:655-74.

26. Sener KT, Durak B, Tanır HM ve ark. Kordosentez Sonuçlarının Değerlendirmesi: 9 Y1llık Deneyim, Türk Jinekoloji ve Obstetrik Derneği Dergisi, 2013;10:151- 157

27. Erdemoğlu M, Kale A, Akdeniz N. Prenatal Tan1 Amaciyla Kordosentez Uygulanan 172 Olgunun Değerlendirilmesi. Dicle Tip Dergisi. 2007;34:7-13

28. Dağlar HK, Kaya B, Şahin HO ve ark. Gaziantep İli Doğum Hastanesi'nde Karyotip Analizi Amaci ile Amniyosentez ve Koryon Villus Örneklemesi Yapılan 268 Olgunun Retrospektif Analizi. Perinatoloji Dergisi. 2011;19:130-136

29. Yüce H, Çelik H, Gürateş B ve ark. Karyotip analizi amaciyla genetik amniyosentez uygulanan 356 olgunun retrospektif analizi. Perinatoloji Dergisi 2006;14:73-76 